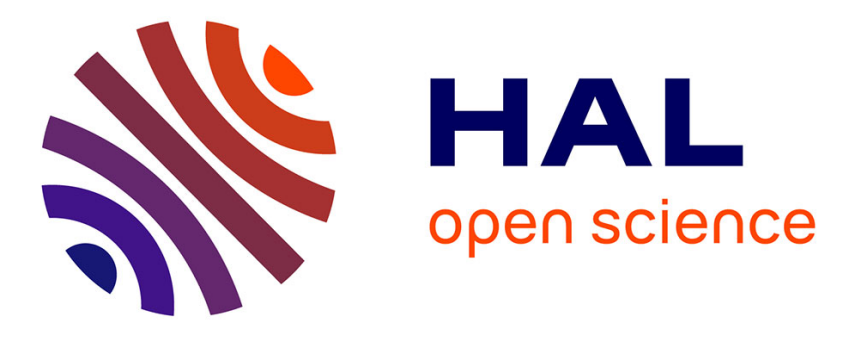

\title{
Priming Resistance to Persuasion decreases adherence to Conspiracy Theories
}

\author{
Eric Bonetto, Jaïs Troian, Florent Varet, Grégory Lo Monaco, Fabien
}

Girandola

\section{- To cite this version:}

Eric Bonetto, Jaïs Troian, Florent Varet, Grégory Lo Monaco, Fabien Girandola. Priming Resistance to Persuasion decreases adherence to Conspiracy Theories. Social Influence, 2018, 13 (3), pp.125-136. 10.1080/15534510.2018.1471415 . hal-02074237

\section{HAL Id: hal-02074237 \\ https://hal-amu.archives-ouvertes.fr/hal-02074237}

Submitted on 20 Mar 2019

HAL is a multi-disciplinary open access archive for the deposit and dissemination of scientific research documents, whether they are published or not. The documents may come from teaching and research institutions in France or abroad, or from public or private research centers.
L'archive ouverte pluridisciplinaire $\mathbf{H A L}$, est destinée au dépôt et à la diffusion de documents scientifiques de niveau recherche, publiés ou non, émanant des établissements d'enseignement et de recherche français ou étrangers, des laboratoires publics ou privés.

\section{(ㅇ)(1) $\$$}

Distributed under a Creative Commons Attribution - NonCommercial - NoDerivatives| 4.0 
Socialinfluence

ISSN: 1553-4510 (Print) 1553-4529 (Online) Journal homepage: http://www.tandfonline.com/loi/psif20

\section{Priming Resistance to Persuasion decreases adherence to Conspiracy Theories}

\section{Eric Bonetto, Jaïs Troïan, Florent Varet, Grégory Lo Monaco \& Fabien Girandola}

To cite this article: Eric Bonetto, Jaïs Troïan, Florent Varet, Grégory Lo Monaco \& Fabien Girandola (2018): Priming Resistance to Persuasion decreases adherence to Conspiracy Theories, Social Influence, DOI: 10.1080/15534510.2018.1471415

To link to this article: https://doi.org/10.1080/15534510.2018.1471415

\section{Published online: 09 May 2018.}

Submit your article to this journal $\square$

Q View related articles $\square$

View Crossmark data ¿ 


\title{
Priming Resistance to Persuasion decreases adherence to Conspiracy Theories*
}

\author{
Eric Bonetto ${ }^{\mathrm{a}}$ (D) Jaïs Troïan ${ }^{\mathrm{a}}$ (D), Florent Varet ${ }^{\mathrm{a}, \mathrm{b}}$ (D), Grégory Lo Monaco ${ }^{\mathrm{a}}$ (D) and \\ Fabien Girandola a iD
}

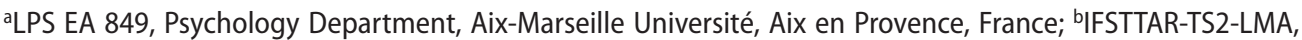
Salon-de-Provence, France

\begin{abstract}
Research in the field of Resistance to Persuasion (RP) has demonstrated that inoculating individuals with counter arguments is effective for lowering their levels of adherence to conspiracist beliefs (CB). Yet, this strategy is limited because it requires specific arguments tailored against targeted conspiracist narratives. Therefore, we investigated whether priming Resistance to Persuasion would reduce individual adherence to $\mathrm{CB}$ among undergraduate student samples. A first study $(N=81)$ demonstrated that participants primed by filling a RP scale had lower CB scores than control participants. This effect was directly replicated twice $(N=205$ and $N=265)$ and confirmed by a mini metaanalysis $(N=519 ; d=.20)$. Practical and theoretical implications are then discussed.
\end{abstract}

\section{ARTICLE HISTORY}

Received 16 February 2018 Accepted 12 April 2018

KEYWORDS

Resistance to Persuasion; priming; meta-cognition; conspiracy theories; inoculation

\section{Introduction}

Conspiracist Beliefs (CB) are unverified and implausible allegations of conspiracy, according to which a preternatural sinister or a powerful group of people pull the strings of significant events (Aaronovitch \& Langton, 2010; Brotherton, French, \& Pickering, 2013). Different surveys using representative European and US samples revealed that a non-negligible proportion of interviewees display some strong or milder form of adherence to $\mathrm{CB}$ (e.g., Oliver $\&$ Wood, 2014). In France for instance, around $22 \%$ of a surveyed sample $(N=2054)$ fully agreed with the statement that 'the government does not really govern and that we do not know who really pulls the strings' (Gyárfášová, Krekó, Mesežnikov, Molnár, \& Morris, 2013). Current social-psychological investigation of $\mathrm{CB}$ provides converging evidence for their role as threat regulating beliefs that satisfy individuals' epistemic and control needs (e.g., Graeupner \& Coman, 2017; Whitson \& Galinsky, 2008). Corroborating this motivated cognition account of CB's function (Jost, Nosek, \& Gosling, 2008; Kunda, 1990), other studies have repeatedly found correlations between $\mathrm{CB}$ adherence and information-processing trait variables (e.g., Leman \& Cinnirella, 2013), and recent studies showed that CB stem from

CONTACT JaïsTroïan jais.ADAM@univ-amu.fr

*The data that supports the findings of this study are openly available on OSF website in Resistance To Persuasion Conspiracy repository at https://osf.io/nb86j/. 
cognitive processes responsible for the detection of illusory patterns in the environment (Landau, Kay, \& Whitson, 2015; Van Prooijen, Douglas, \& De Inocencio, 2017).

Far from being innocuous distorted beliefs about the social world and its organization, $\mathrm{CB}$ can have tremendous influence on individual behavior. For instance, Jolley and Douglas (2014a) demonstrated that exposure to beliefs of the CB kind reduced voting intentions because of increased feelings of political powerlessness. As these authors showed in another study (Jolley \& Douglas, 2014a; Study 2), exposure to CB was able to significantly decrease participants' intentions to reduce their carbon footprint through the same elicited feelings of powerlessness. CB's negative consequences were also observed in a wide range of domains, such as health behaviors (Jolley \& Douglas, 2014b) or acceptance of scientific knowledge (Lewandowsky, Gignac, \& Oberauer, 2013). Consequently, the recent surge in online 'fake news' (Mustafaraj \& Metaxas, 2017) has caught the public's interest and stimulated the search for factors that could potentially decrease individual adherence to CB.

So far, among the various approaches to $\mathrm{CB}$ adherence deterrence, some have been based on McGuire's (1961) work upon Resistance to Persuasion (RP) through inoculation (Banas \& Miller, 2013; Jolley \& Douglas, 2014b, Study 2; Jolley \& Douglas, 2017). Shortly, Inoculation Theory (Papageorgis \& McGuire, 1961) proposes that individuals can be literally inoculated against persuasive attempts (i.e. counter-attitudinal messages) in the same way organisms can be immunized against viral diseases. To achieve the desired effect, a successful inoculation must comprise two key elements: a threat and refutational material. The threat should trigger individuals' motivation to engage in counter-argumentation with the help of the refutational material contained in the inoculation message (Compton \& Pfau, 2005; Pfau et al., 1997). The effectiveness of Inoculation Theory-based interventions was corroborated by a meta-analysis of 41 studies (Banas \& Rains, 2010), and successfully applied to prevent adherence to CB. In one study by Jolley and Douglas (2014b, Study 2), participants presented with pro-vaccine arguments were prevented from having decreased intentions to vaccinate as participants exposed to conspiracist anti-vaccine arguments. This work was recently replicated and showed that exposing participants to anti-conspiracy arguments increased their intentions to vaccinate a fictional child (Jolley \& Douglas, 2017). This effect only occurred when inoculation was done before exposure to pro-conspiracy arguments about vaccines. Similarly, Banas and Miller (2013) found successful inoculation effects after exposure to a $40 \mathrm{~min}$ long message (taken from a conspiracist documentary film), even when participants were warned that inoculation was an attempt to influence their rate of attitude change.

As these results demonstrate, it is possible and effective to implement individual resistance to conspiracist persuasion through inoculation. However, one main limitation of doing so is that it requires specific counter arguments tailored against specific $\mathrm{CB}$, which can constitute a real barrier in terms of real-world interventions. Ideally, applied researchers would look for 'broad' factors that could be easily implemented in messages targeting a wide audience. Fortunately, as Inoculation Theory specifies, refutational content is just one of two components of the intervention, the other being a motivation to engage in counter-argumentation. One could therefore wonder if simply eliciting meta-cognitions about RP (Briñol, Rucker, Tormala, \& Petty, 2004; Jost, Kruglanski, \& Nelson, 1998) would also lead to a reduction in adherence to a wide range of $\mathrm{CB}$, without having the problem of defining specific arguments for each different conspiracist content. 
Thus, the present contribution aims to test whether merely priming RP (Knowles \& Linn, 2004) would be sufficient to render individuals less likely to adhere to conspiracist narratives without providing them with any counter-arguments. To do so, we decided to use Uhlmann and Cohen's (2007) paradigm. These authors investigated the effects of an 'objectivity prime' on activation of gender-stereotypical thoughts. The task they designed was straightforward: subjects in the priming condition first had to fill a 4-item scale (e.g., 'My decision-making is rational and objective'), which rendered the concept of objectivity cognitively accessible to them. Their priming method was replicated (Lindner, Graser, \& Nosek, 2014) indicating that it should be rather reliable. Inspired by Uhlman and Cohen's method, we wanted to prime Resistance to Persuasion (RP) by making subjects fill the Resistance to Persuasion scale (Briñol et al., 2004), which consists in a series of statements regarding one's beliefs about one's susceptibility to persuasion (e.g. 'I usually do not change what I think after a discussion'). We hypothesized that participants primed with RP would be less likely to adhere to conspiracist narratives and therefore should display lower scores of conspiracist ideation on a standardized scale. We decided to put this hypothesis to the test across three studies (one for first evidence, two direct replications) and to meta-analyze them (see Goh, Hall, \& Rosenthal, 2016). This would be done to firmly establish the presence of a replicable effect and gain precise estimates of its size before trying to explore potential candidates for mediation and moderation (see Simons, 2014).

All three studies were conducted in accordance with the 1964 Helsinki declaration (WMO, 1964) and its later amendments, the ethical principles of the French Code of Ethics for Psychologists (CNCDP, 2012), and the 2016 APA Ethical Principles of Psychologists and Code of Conduct (APA, 2017).

\section{Study 1}

\section{Method}

Design and participants. This study was based on a 2 (Priming: RP vs. Control) single factor between-subjects design. To operationalize RP priming, we used a modified version of Uhlmann and Cohen's (2007) paradigm. Half of participants were primed by making them fill the Resistance to Persuasion scale (Briñol et al., 2004). Because the original scale was in English, we validated a French version (using backwards translation by a native speaker) among a sample of the general population (online, $N=766$ ). Both exploratory (explained $46.2 \%$ of total variance, $\mathrm{KMO}=.84$; Bartlett's test of sphericity: $\chi^{2}=2194.77, p<.001$ ) and confirmatory analyses $(\mathrm{CMIN}=244.88$; CMIN $/ \mathrm{Df}=4.6$; GFI $=.95$; $\mathrm{RMSEA}=.07$; $\mathrm{SRMR}=.06 ; \mathrm{CFI}=.91 ; \mathrm{NFI}=.89 ; \mathrm{IFI}=.91)$ revealed that an optimal, two-dimension, 12-item solution which was retained (see Bentler, 1992; Hu \& Bentler, 1995; Jöreskog and Sörbom, 2002). The other half of participants was invited to fill 12 items of the Positive and Negative Affect Scale (PANAS; Crawford \& Henry, 2004) as a neutral control (see Rosenblatt, Greenberg, Solomon, Pyszczynski, \& Lyon, 1989). This was done to rule out filling up any measure as an alternative explanation for the priming effect. Indeed, Uhlmann \& Cohen's original protocol did not address this issue, instead, participants in the control condition filled the prime after the dependent variable.

Power analyses were conducted to determine sample size by using Uhlmann and Cohen's original effect size $(d=.76$; Study 1$)$. For performing a two-tailed independent $t$-test with 
$80 \%$ power, at least 29 participants per conditions were needed $(N=58)$. Guaranteeing optimal power, our sample consisted of 81 undergraduate students $\left(2.5 \%\right.$ male; $M_{\text {age }}=18.79$, $S D=1.22$ ), randomly assigned to one of the two conditions.

Material and procedure. Due to the exploratory nature of the prime, we decided to use a laboratory setting. A computerized questionnaire was thus proposed to undergraduate psychology students whom came to the laboratory in exchange for course credits. As a cover story, participants were told that a study was being conducted on the link between personality and societal beliefs. After filling up the RP scale or the PANAS, participants were asked to fill the Generic Conspiracist Beliefs scale (GCBS; Brotherton, French, \& Pickering, 2013). The GCBS consists in a series of 15 statements about various conspiracies (e.g., 'Certain significant events have been the result of the activity of a small group who secretly manipulate world events'). Participants were instructed to rate their agreement for each statement on 5-point Likert scales ranging from 1 (not true at all) to 5 (very true). This widely used scale was chosen because it allows for tapping into global 'conspiracist ideation' (Lantian, Muller, Nurra, \& Douglas, 2016).

\section{Results}

Randomization check. Group sizes were almost equal ( $N=41$ in the priming condition, $49.4 \%$ of participants), $\chi^{2}(1)=.01, p=.91$, and male subjects were only 2 , each being allocated to a different condition. No problematic age difference $t(79)=-.29, p=.77$ was observed between our two conditions.

Conspiracist Beliefs. Since Swami et al. (2017) recommend assessing the GCBS properties each time a global score is to be used, exploratory factor analyses were conducted (Maximum Likelihood, Promax rotation, Costello \& Osborne, 2005). It yielded an adequate, 4 -dimension solution $\left(K M O=.84\right.$; Bartlett's $\chi^{2}(105)=542.80, p<.001 ; 56.56 \%$ of total explained variance). Reliability of the scale was deemed satisfying (Cronbach's $\alpha=.89$ ) and we proceeded to score computation. An independent sample $t$-test revealed a moderate main effect of RP priming upon adherence to $\mathrm{CB}$. As expected, participants in the RP priming condition displayed lower adherence to $\mathrm{CB}, M=1.87, \mathrm{SD}=.73$, than participants in the control condition $M=2.28, S D=.73, t(79)=2.57, p=.012, d=.57$, with a $M_{\text {diff }}=.42,95 \%$ CI $[.09, .74]$. Therefore, our hypothesis cannot be rejected.

\section{Discussion}

As predicted, RP priming significantly decreased participants' adherence to CB. However, because this novel effect was obtained on a small sample, strict replication studies with larger sample sizes were needed to assess its robustness, ensure it was not a false positive and better estimate the population effect size (which might be smaller than the obtained $d=.57$ ). For those reasons, we proceeded to a second, online study.

\section{Study 2}

Further research was needed to ensure that the effects of RP priming were not due to (a) random variations (b) flaws in the laboratory procedure (c) specific characteristics of our local university sample. We thus decided to carry out an online study on a larger sample 
of French undergraduates from different parts of the country. We hypothesized that RP priming would lead to a decrease in participants' adherence to $\mathrm{CB}$, with a mean difference comprised within the $95 \%$ CI $[.09, .74]$ boundaries from study 1 .

\section{Method}

Design and Participants. This second study used the same computerized questionnaire as study 1 . This time, power analyses were conducted by using Study 1's effect size $(d=.57)$. For conducting a two-tailed independent t-test with $80 \%$ power, at least 50 subjects per conditions were needed (i.e., a total of 100). Because more and more individuals answer online surveys as they are accessible on social networks groups, we decided to regularly check our sample size and stop data collection once conditions reached at least 100 participants each (ensuring enough power). Our sample consisted of 205 undergraduate students $\left(15.1 \%\right.$ male; $\left.M_{\text {age }}=21.51, S D=4.57\right)$, randomly assigned to one of the two experimental conditions according to their date of birth. Their participation to the study was completely voluntary and they were offered neither money nor credit course in exchange.

Material and Procedure. The online computerized questionnaire was distributed among general French students' (from fields in the arts and social science) social network groups (i.e., Facebook) and was introduced as a study about the 'relationship between personality and opinions societal issues'. RP priming was induced following the same methodology as in Study 1. Participants then had to fill the GCBS scale and give information about their age and gender.

\section{Results}

Randomization check. There was no consequent between-group differences in terms of size $\left(N_{\text {prime }}=94 ; N_{\text {control }}=111\right), \chi^{2}(1)=1.41, p=.24$, age, $t(203)=1.28, p=.20$, or gender, $\chi^{2}(1)=1.19, p=.28$.

Conspiracist Beliefs. The GCBS demonstrated an adequate 3-dimension structure (Maximum Likelihood, Promax rotation; $K M O=.88$; Bartlett's $\chi^{2}(105)=1491.42, p<.001$; $52.89 \%$ of total explained variance). Cronbach's $\alpha$ for GCBS was again of .89, allowing for score computation. We conducted an independent sample $t$-test, which showed a main effect of our prime upon adherence to CB. As predicted, participants in the RP priming condition declared less adherence to $\mathrm{CB}, M=2.74, \mathrm{SD}=.78$, than control participants, $M=2.97, S D=.73, t(203)=2.20, p=.029, d=.31$, with a $M_{\text {diff }}=.23,95 \%$ CI [.02,.44]. The mean difference fell within the boundaries of Study 1's mean difference 95\% CI [.09,.74], though almost twice smaller. Once again, our hypothesis cannot be rejected.

\section{Discussion}

This second study allowed us to confirm the existence of an RP priming effect upon adherence to CB. Nevertheless, because the effect was twice smaller than that of Study 1, another sufficiently powered study was be conducted to further corroborate the presence of this effect, along with finer estimates of the effect size. 


\section{Study 3}

A final online study on another sample of French undergraduates was carried out. Again, we hypothesized that RP priming would lead to a decrease in participants' adherence to CB, with a mean difference comprised within the 95\% CI [.02,.44] boundaries from Study 2.

\section{Method}

Design and participants. This study was based on the same design as Study 2. Power analyses were conducted by using Study 2's effect size $(d=.31)$. Because we had solid prior evidence to back up our directional hypothesis we set the parameters for a one-tailed independent $t$-test with $80 \%$ power, at least 130 subjects per conditions were needed (i.e., a total of 260 ). Data collection stopping rules were the same than in Study 2 except that we aimed to stop once the $N=260$ cutoff was reached. Our sample is made of 265 undergraduate students $\left(22.3 \%\right.$ male; $\left.M_{\text {age }}=20.27, S D=1.83\right)$, randomly assigned to one of the two experimental conditions according to their date of birth. Participation was voluntary, no compensation was offered, just like in Study 2.

Material and procedure. An online questionnaire was disseminated among general French students' (from fields in the arts and social sciences, though different ones to avoid recruiting participants from Study 2) social network groups, following the same methodology as described in Study 2.

\section{Results}

Randomization check. There was no remarkable between group differences in terms of size $\left(N_{\text {prime }}=128 ; N_{\text {control }}=137\right), \chi^{2}(1)=.31, p=.58$, age, $t(263)=1.56, p=.12$, or gender, $\chi^{2}(1)=1.07, p=.30$.

Conspiracist Beliefs. Again, the GCBS showed an adequate 3-dimension structure (Maximum Likelihood, Promax rotation; $K M O=.88$; Bartlett's $\chi^{2}(105)=1671.10, p<.001$; $49.86 \%$ of total explained variance). Reliability of the GCBS was adequate, $\alpha=.88$, enabling score computation. An independent sample $t$-test showed the expected main effect of RP priming upon adherence to $\mathrm{CB}$. Once again, participants in the priming condition had lower levels of adherence to $\mathrm{CB}, M=2.49, S D=.75$, than control participants, $M=2.76$, $S D=.72, t(263)=2.92, p=.004$, with a $M_{\text {diff }}=.26,95 \%$ CI $[.09, .44]$, well within Study 2 's mean difference boundaries 95\% CI [.02,.44]. The effect was replicated in the predicted direction and was of equivalent magnitude than in study $2(d=.36)$.

\section{Discussion}

This last study allowed us to confirm the theoretically predicted effect of RP priming upon individuals' adherence to CB. We had sufficient power to detect the effect and its size seemed to have stabilized around $d=.30$. We therefore decided to meta-analyze our three studies to gain finer-grained estimates of the population effect size on a large sample. 


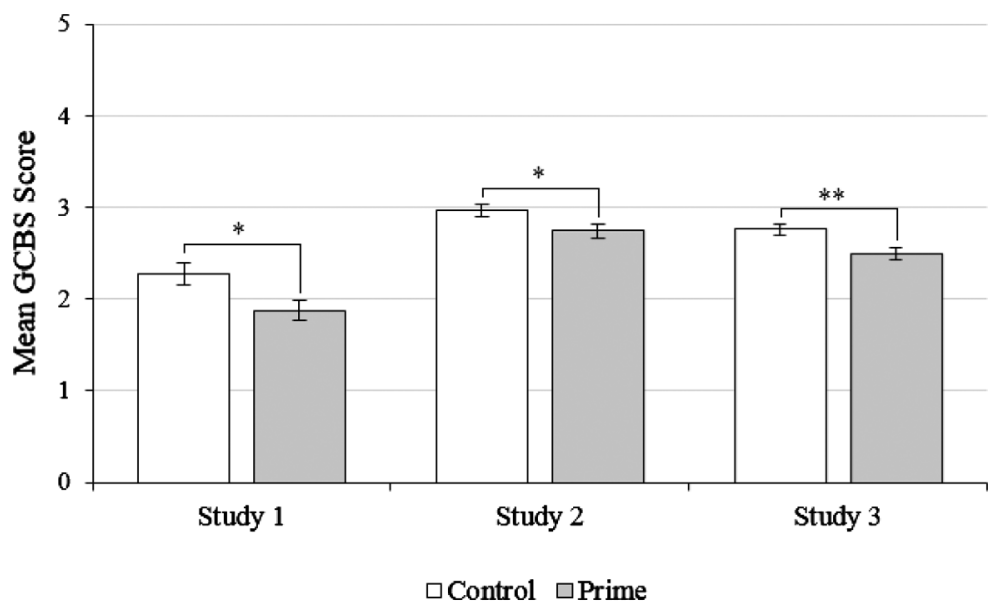

Figure 1. Mean differences in adherence to CB between control and RP priming groups across studies. Note: Error bars represent SEs. ${ }^{*} p<.05 ;{ }^{* *} p<.01$.

\section{Meta-analysis}

To meta-analyze our results (Goh et al., 2016), we aggregated databases from study 1, 2 and 3 (see figure 1). It yielded a $N=519$ sample $\left(M_{\text {age }}=22.7, S D=8.3,18.2 \%\right.$ male). A mixed model was then computed with studies as a random factor, RP priming as a fixed effect and adherence to $\mathrm{CB}$ as the dependent variable, according to the following equation: $c b \sim$ $1+(1 \mid s t u d y)+$ prime. The model $\left(\mathrm{AIC}=1202.43, r_{\text {conditional }}^{2}=.21\right)$ confirmed the effect of $\mathrm{RP}$ priming upon adherence to $\mathrm{CB}, F(1,515)=7.97 ; p=.005$, despite considerable variations in CB levels across studies $\left(r_{\text {intercept }}^{2}=.20\right)$. However, the effect size was a bit smaller than the previously obtained one with an intercept $b=-.10,95 \%$ IC $[-.16 ;-.03]$ and a $r_{\text {marginal }}^{2}=.01$ or $d=.20$. Therefore, RP priming was found to have a small but robust effect upon adherence to $\mathrm{CB}$.

\section{General discussion}

These three studies provided converging evidence for the existence of an effect of RP priming upon adherence to $\mathrm{CB}$ (for a discussion about the benefits of firmly establishing main effects through direct replication before proceeding to further investigation, see Simons, 2014). Taken together, these replicated results demonstrate how a minimal manipulation for priming RP can negatively impact agreement with conspiracist narratives, even in the absence of specific counter-arguments.

It must be noted that our investigation was not only theoretically motivated. Many studies demonstrate that contextual triggers, such as threats, can increase adherence to CB (Graeupner \& Coman, 2017). While these discoveries have precious value for further exploring the social-cognitive underpinnings of $\mathrm{CB}$ adherence, they are less suited for practical interventions. On the contrary, deepening our understanding of RP priming could yield straightforward implications and provide novel directions for interventions aimed at reducing individuals' adherence to $\mathrm{CB}$. As we have seen, some interventions are, for obvious reasons, focused on providing individuals with valid information for inoculating them with 
rational counter arguments prior to conspiracy theories exposure (Jolley \& Douglas, 2014b). The main idea behind these kinds of actions is that poor logic and inaccurate knowledge (or perceptions) are at the core of one's adherence to irrational beliefs such as CB. If faulty reasoning can constitute a fertile ground for $\mathrm{CB}$ and can be considered as a 'risk factor', our studies demonstrated that meta-cognitive elements can play an important role in triggering CB. Thus, our technique could be tested in field research for investigating its effects upon online information processing. For instance, asking individuals to fill some of the RP scale's items before accessing content of the conspiracist or 'fake news' type could lead to lower levels of individuals' adherence to those contents. Since this technique is a non-intrusive and easily concealable way of priming RP, its efficiency for increasing the effectiveness of interventions aimed at fighting CB (by promoting critical thinking, or aiming at increasing pupils' value complexity for instance, see Liht \& Savage, 2013) could be assessed in the future. For instance, RP based interventions could range from teaching pupils a special class on critical thinking (i.e., promoting RP as a meta-cognitive style) to exposing students to RP priming material (i.e., a text or even the RP scale) one or several times. Measures could be varied in form (e.g., adherence to a 'fake' conspiracy theory created by the experimenters) and in time delay (e.g., one week after intervention). In fact, because this series of studies was designed to provide a 'proof of concept', we think that future research should be conducted to transpose RP priming to real-life contexts and assess the dynamics of its effects upon CB (e.g., how long would the effect last?).

Although the present line of research allowed to highlight interesting effects, it contained some limitations that should constrain our inferences. First, we should be careful when trying to generalize these results beyond the WEIRD populations used in these samples (Henrich, Heine, \& Norenzayan, 2010), that also comprised mostly female individuals. Though there is no theoretical rationale for expecting gender differences in priming effects upon adherence to narratives such as $\mathrm{CB}$, our protocols were not tailored to firmly rule out this possibility. Putting aside issues of generalizability, we should also be careful until conceptual replications of this effect are provided. Accordingly, further research should be carried out using different kinds of primes (scrambled words, video footage, press articles or even subliminal exposure related to RP) and other dependent variables (such as pattern detection in random noise or scenarios that tap into 'everyday life' conspiracist ideation, see Kay, Whitson, Gaucher, \& Galinsky, 2009; Landau et al., 2015), to gain a more accurate depiction of the processes underlying RP priming.

We think conceptual replications would also allow for removing potential biases inherent to the present experimental design. For instance, because of the close temporal proximity between our RP prime scale and the CB measure (which can be palliated through delayed measurement and distractor tasks between the prime and the dependent variable), it could be argued that the observed decrease might be due to social desirability or experimenter demands. That is, our effect could be the result of participant reactance because they are presented with a CB measure just after filling up items about their willingness to consider alternative viewpoints (leading to suspicion on their behalf). If true, this would nonetheless imply that anti-CB interventions based on social norms salience could be expected to yield small-to-medium replicable decreases in (at least) publicly declared adherence to CB (potentially impeding their diffusion through online-offline communications) if not adherence to them. Thus, this limitation in our design calls for further research assessing 
alternative hypotheses linked with social influence processes (e.g., conformity) that could yield interesting practical and theoretical outcomes.

Finally, subsequent studies should be carried out to assess RP priming effects in the context of conspiracist attitude-change following 'ecological' exposure to conspiracist persuasive attempts (such as Banas \& Miller's, 201340 min long video footage), and using measures of specific $\mathrm{CB}$. It is possible that RP priming might be ineffective against $\mathrm{CB}$ that are very important to one's belief system/identity and that one maybe strongly motivated to defend. Having discussed the methodological boundaries of our RP priming effect, we can now examine theoretical perspectives regarding its nature.

First, in the absence of mediational investigation of the processes that lead to decreased adherence to $\mathrm{CB}$ after $\mathrm{RP}$ priming, no firm conclusion can be made regarding what this prime actually triggers. In fact, one could think of several ways RP priming could affect CB adherence. When taking a closer look at the scale, one cannot help notice the similarity between the RP scale items (i.e., 'I find my opinions to be changeable', 'It is hard for me to change my ideas', see Knowles \& Linn, 2004, p;.90) and the concept of Open-Minded Cognition (Price, Ottati, Wilson, \& Kim, 2015), which is defined as a willingness to consider ideas and opinions that are different and sometimes contradict individuals' own views. Because Open-Minded Cognition is part of a broader 'analytical reasoning' style it has been found to be associated with lower levels of conspiracist ideation (Swami, Voracek, Stieger, Tran, \& Furnham, 2014). Though these results are isolated and though the link between Open-Minded Cognition and decreased information-processing biases is unclear (see Brandt, Chambers, Crawford, Wetherell, \& Reyna, 2015), one cannot firmly exclude a possible mediation of RP priming effects on CB through an increased Open-Minded cognitive style.

Second, our studies rest on a meta-cognitive assumption (Jost et al., 1998) according to which priming individuals with the concept of RP will increase their motivation to resist persuasion because it leads them to think about their own information processing style. But what if RP priming did not simply render the concept of resisting persuasion accessible and, instead, made individuals feel more confident about their own ability to resist (Jacks \& O'Brien, 2004)? This increased confidence could impact their sensation of being in control which would explain a reduced need to appeal to narratives of the CB kind. Again, these possibilities point at the need to further investigate the motivational mechanisms at play behind RP priming (e.g., changes in rational-epistemic motivation; Ståhl \& van Prooijen, 2018).

Furthermore, as we have seen, the meta-analyzed effect of our RP manipulation upon adherence to CB was robust but of small size $(d=.20)$. Though a small size says nothing about the meaningfulness of RP priming effects because the manipulation was truly minimal, it indicates that potent moderators (such as individual difference variables) could be used to specify their range and boundary conditions. As can be deduced from figure 1, our undergraduate samples displayed low-to-moderate levels of adherence to $\mathrm{CB}$, potentially leading to a 'floor' effect. In line with this observation, we argue that RP priming might behave differently in samples displaying higher levels of adherence to $\mathrm{CB}$, that is, prior adherence to $\mathrm{CB}$ (at the individual or population level) could constitute an important moderator. Other examples of such moderators are traits and constructs already known for their positive links with CB such as the Need for Closure (Leman \& Cinnirella, 2013; Webster \& Kruglanski, 1994), Need for Order (Abalakina-Paap, Stephan, Craig, \& Gregory, 1999; Swami, 2012), or even the preference for Manichean narratives, (i.e., simplified teleological accounts of complex random events; Oliver \& Wood, 2014). In a similar fashion, variables 
that are already known to moderate priming effects could provide interesting theoretical insights (e.g., Preference for Consistency, Cialdini, Trost, \& Newsom, 1995).

In conclusion, this set of studies opens new research avenues on the link between RP and conspiracist narratives, for both fundamental and applied purposes. Moreover, our results constitute first evidence for the potential usefulness of tapping into core meta-cognitive constructs (Jost et al., 1998) such as RP when trying to promote vigilance against $\mathrm{CB}$ among the public. Future lines of investigation will broaden our understanding of its inner workings, hopefully to provide ever more efficient ways of deterring CB through social-psychological interventions.

\section{Disclosure statement}

The authors declare that there are no potential conflicts of interest with respect to the research, authorship, and/or publication of this article.

\section{Funding}

This work was funded by the French Ministry of Research and Education and by the region ProvenceAlpes-Côte d'Azur.

\section{ORCID}

Eric Bonetto (iD http://orcid.org/0000-0002-0824-1103

Jaïs Troïan (D) http://orcid.org/0000-0003-2285-4114

Florent Varet (iD http://orcid.org/0000-0002-5248-3740

Grégory Lo Monaco (iD http://orcid.org/0000-0003-1150-539X

Fabien Girandola (D) http://orcid.org/0000-0002-1253-1728

\section{References}

Aaronovitch, D., \& Langton, J. (2010). Voodoo histories: The role of the conspiracy theory in shaping modern history. New York, NY: Riverhead Books.

Abalakina-Paap, M., Stephan, W. G., Craig, T., \& Gregory, W. L. (1999). Beliefs in conspiracies. Political Psychology, 20, 637-647. doi:10.1111/0162-895X.00160

American Psychological Association. (2017). Ethical principles of psychologists and code of conduct. Retrieved from http://www.apa.org/ethics/code/index.aspx

Banas, J .A., \& Miller, G. (2013). Inducing resistance to conspiracy theory propaganda: Testing inoculation and metainoculation strategies. Human Communication Research, 39, 184-207. doi:10.1111/hcre.12000

Banas, J. A., \& Rains, S. A. (2010). A Meta-analysis of research on inoculation theory. Communication Monographs, 77, 281-311. doi:10.1080/03637751003758193

Bentler, P. M. (1992). On the fit of models to covariances and methodology. Psychological Bulletin, 112, 400-404.

Brandt, M. J., Chambers, J. R., Crawford, J. T., Wetherell, G., \& Reyna, C. (2015). Bounded openness: The effect of openness to experience on intolerance is moderated by target group conventionality. Journal of Personality and Social Psychology, 109, 549-568.

Briñol, P., Rucker, D. D., Tormala, Z. L., \& Petty, R. E. (2004). Individual differences in resistance to persuasion: The role of beliefs and meta-beliefs. In E. S. Knowles \& J. A. Linn (Eds.), Resistance and persuasion (pp. 83-104). Mahwah, N. J: Lawrence Erlbaum Associates.

Brotherton, R., \& French, C. C., \& Pickering, A. D. (2013). Measuring belief in conspiracy theories: The generic conspiracist beliefs scale. Frontiers in Psychology, 4, 279. doi: 10.3389/fpsyg.2013.00279 
Cialdini, R. B., Trost, M. R., \& Newsom, J. T. (1995). Preference for consistency: The development of a valid measure and the discovery of surprising behavioral implications. Journal of Personality and Social Psychology, 69, 318-328.

Commission Nationale Consultative de Déontologie des Psychologues (2012). Code de déontologie des psychologues (1996, Amended February, 2012). Retrieved from http://www.cncdp.fr/index. $\mathrm{php} /$ code-de-deontologie/code-de-deontologie-2012

Compton, J. A., \& Pfau, M. (2005). Inoculation theory of resistance to influence at maturity: Recent progress in theory development and application and suggestions for future research. Annals of the International Communication Association, 29, 97-146. doi:10.1080/23808985.2005.11679045

Costello, A. B., \& Osborne, J. W. (2005). Best practices in exploratory factor analysis: Four recommendations for getting the most from your analysis. Practical assessment, research \& evaluation, 10, 1-9.

Crawford, J. R., \& Henry, J. D. (2004). The Positive and Negative Affect Schedule (PANAS): Construct validity, measurement properties and normative data in a large non-clinical sample. British Journal of Clinical Psychology, 43, 245-265. doi:10.1348/0144665031752934

Goh, J. X., Hall, J. A., \& Rosenthal, R. (2016). Mini Meta-analysis of your own studies: Some arguments on why and a primer on how. Social and Personality Psychology Compass, 10, 535-549. doi:10.1111/ spc3.12267

Graeupner, D., \& Coman, A. (2017). The dark side of meaning-making: How social exclusion leads to superstitious thinking. Journal of Experimental Social Psychology, 69, 218-222. doi:10.1016/j. jesp.2016.10.003

Gyárfášová, O., Krekó, P., Mesežnikov, G., Molnár, C. and Morris, M. (2013). The conspiratorial mindset in the age of transition: Conspiracy theories in France, Hungary and Slovakia-survey results. Retrieved from http://www.ivo.sk/buxus/docs//publikacie/subory/The_Conspiratorial_ Mindset_in_an_Age_of_Transition.pdf

Henrich, J., Heine, S. J., \& Norenzayan, A. (2010). Most people are not WEIRD. Nature, 466, 29. doi:10.1038/466029a

Hu, L. T., \& Bentler, P. (1995). Evaluating model fit. In R. H. Hoyle (Ed.), Structural Equation Modeling. Concepts, Issues, and Applications (pp. 76-99). London: Sage.

Jacks, J. Z., \& O’Brien, M. E. (2004). Decreasing resistance by affirming the self. In E. S. Knowles \& J. A. Linn (Eds.), Resistance and persuasion (pp. 235-258). Mahwah, N. J: Lawrence Erlbaum Associates.

Jolley, D., \& Douglas, K. M. (2014a). The social consequences of conspiracism: Exposure to conspiracy theories decreases intentions to engage in politics and to reduce one's carbon footprint. British Journal of Psychology, 105, 35-56. doi:10.1111/bjop.12018

Jolley, D., \& Douglas, K. M. (2014b). The effects of anti-vaccine conspiracy theories on vaccination intentions. PLoS ONE, 9, e89177. doi:10.1371/journal.pone.0089177

Jolley, D., \& Douglas, K. M., (2017). Prevention is better than cure: Addressing anti-vaccine conspiracy theories. Journal of Applied Social Psychology, 47, 459-469. doi:10.1111/jasp.12453

Jöreskog, K. G., \& Sörbom, D. (2002). LISREL 8: Structural equation modeling with SIMPLIS command language. Fifth Printing. Lincolnwood, IL: Scientific Software International.

Jost, J. T., Kruglanski, A. W., \& Nelson, T. O. (1998). Social metacognition: An expansionist review. Personality and Social Psychology Review, 2, 137-154. doi:10.1207/s15327957pspr0202_6

Jost, J. T., Nosek, B. A., \& Gosling, S. D. (2008). Ideology: Its resurgence in social, personality, and political psychology. Perspectives on Psychological Science, 3, 126-136. doi:10.1111/j.17456916.2008.00070.x

Kay, A. C., Whitson, J. A., Gaucher, D., \& Galinsky, A. D. (2009). Compensatory control: Achieving order through the mind, our institutions, and the heavens. Current Directions in Psychological Science, 18, 264-268. doi:10.1111/j.1467-8721.2009.01649.x

Knowles, E. S., \& Linn, J. A. (2004). Resistance and Persuasion. Mahwah, N. J.: Lawrence Erlbaum Associates.

Kunda, Z. (1990). The case for motivated reasoning. Psychological Bulletin, 108, 480-498. doi:10.1037/0033-2909.108.3.480

Landau, M. J., Kay, A. C., \& Whitson, J. A. (2015). Compensatory control and the appeal of a structured world. Psychological Bulletin, 141, 694-722. 
Lantian, A., Muller, D., Nurra, C., \& Douglas, K. M. (2016). Measuring belief in conspiracy theories: Validation of a French and English single-item scale. International Review of Social Psychology, 29, 1-14. doi:10.5334/irsp.8

Leman, P. J., \& Cinnirella, M. (2013). Beliefs in conspiracy theories and the need for cognitive closure. Frontiers in psychology, 4, 378. doi:10.3389/fpsyg.2013.00378

Lewandowsky, S., Gignac, G. E., \& Oberauer, K. (2013). The role of conspiracist ideation and worldviews in predicting rejection of science. PLoS ONE, 8, e75637. doi:10.1371/journal.pone.0075637

Liht, J., \& Savage, S. (2013). Preventing violent extremism through value complexity: Being Muslim being British. Journal of Strategic Security, 6, 44-46.

Lindner, N. M., Graser, A., \& Nosek, B. A. (2014). Age-based hiring discrimination as a function of equity norms and self-perceived objectivity. PLoS ONE, 9, e84752. doi:10.1371/journal. pone.0084752

McGuire, W.J. (1961). Resistance to persuasion conferred by active and passive prior refutation of the same and alternative counterarguments. The Journal of Abnormal and Social Psychology, 63(2), 326-332. doi:10.1037/h0048344

Mustafaraj, E., \& Metaxas, P. T. (2017). The fake news spreading plague: Was it Preventable?. arXiv preprint arXiv:1703.06988. Retrieved from https://arxiv.org/abs/1703.06988v1

Oliver, J. E., \& Wood, T. J. (2014). Conspiracy theories and the paranoid style(s) of mass opinion. American Journal of Political Science, 58, 952-966. doi:10.1111/ajps.12084

Papageorgis, D., \& McGuire, W. J. (1961). The generality of immunity to persuasion produced by pre-exposure to weakened counterarguments. The Journal of Abnormal and Social Psychology, 62, 475-481. doi:10.1037/h0048430

Pfau, M., Tusing, K. J., Koerner, A. F., Lee, W., Godbold, L. C., Penaloza, L. J., \& Hong, Y. H. (1997). Enriching the inoculation construct: The role of critical components in the process of resistance. Human Communication Research, 24, 187-215. doi:10.1111/j.1468-2958.1997.tb00413.x

Price, E., Ottati, V., Wilson, C., \& Kim, S. (2015). Open-minded cognition. Personality and Social Psychology Bulletin, 41, 1488-1504. doi:10.1177/0146167215600528

Rosenblatt, A., Greenberg, J., Solomon, S., Pyszczynski, T., \& Lyon, D. (1989). Evidence for terror management theory: I. The effects of mortality salience on reactions to those who violate or uphold cultural values. Journal of Personality and Social Psychology, 57, 681-690. doi:10.1037/00223514.57.4.681

Simons, D. J. (2014). The value of direct replication. Perspectives on Psychological Science, 9, 76-80. doi:10.1177/1745691613514755

Ståhl, T., \& van Prooijen, J. W. (2018). Epistemic rationality: Skepticism toward unfounded beliefs requires sufficient cognitive ability and motivation to be rational. Personality and Individual Differences, 122, 155-163. doi: 10.1016/j.paid.2017.10.026

Swami, V. (2012). Social psychological origins of conspiracy theories: The case of the jewish conspiracy theory in malaysia. Frontiers in Psychology, 3, 280. doi:10.3389/fpsyg.2012.00280

Swami, V., Voracek, M., Stieger, S., Tran, U. S., \& Furnham, A. (2014). Analytic thinking reduces belief in conspiracy theories. Cognition, 133, 572-585.

Swami, V., Barron, D., Weis, L., Voracek, M., Stieger, S., \& Furnham, A. (2017). An examination of the factorial and convergent validity of four measures of conspiracist ideation, with recommendations for researchers. PLOS ONE, 12, e0172617. doi:10.1371/journal.pone.0172617

Uhlmann, E. L., \& Cohen, G. L. (2007). "I think it, therefore it's true": Effects of self-perceived objectivity on hiring discrimination. Organizational Behavior and Human Decision Processes, 104, 207-223. doi:10.1016/j.obhdp.2007.07.001

Van Prooijen, J. W., Douglas, K. M., \& De Inocencio, C. (2017). Connecting the dots: Illusory pattern perception predicts belief in conspiracies and the supernatural. European Journal of Social Psychology,. doi:10.1002/ejsp.2331

Webster, D. M., \& Kruglanski, A. W. (1994). Individual differences in need for cognitive closure. Journal of Personality and Social Psychology, 67, 1049-1062. doi:10.1037/0022-3514.67.6.1049

Whitson, J. A., \& Galinsky, A. D. (2008). Lacking control increases illusory pattern perception. Science, 322, 115-117. doi:10.1126/science. 1159845

World Medical Organization. (1964). Recommendations guiding physicians in biomedical research involving human subjects. Helsinki. 